UDC 159.964.2:141.82

https://doi.org/10.18485/ms_zmss.2020.97.4

\author{
Alexej Žerebin \\ Staatliche Pädagogische Aleksandr Herzen-Universität Russlands \\ Philologische Fakultät \\ Sankt-Petersburg \\ zerebin@mail.ru
}

\author{
Alexei Zherebin \\ Herzen State Pedagogical University of Russia \\ Institute of Philology \\ Sankt-Peterburg \\ zerebin@mail.ru
}

\title{
RUSSISCHER FREUDOMARXISMUS IM DISKURSFELD DER HISTORISCHEN AVANTGARDE
}

\section{RUSSIAN FREUDO MARXISM IN THE DISCURSIVE FIELD OF THE HISTORICAL AVANT-GARDE}

Der Artikel enthält eine Analyse der Überzeugungen und Argumente, die das utopische Projekt des Freudomarxismus im Kontext des ästhetischen Programms der russischen Avantgarde charakterisieren. Die freudo-marxistische Synthese basiert auf dem avantgardistischen Modell der Lebensschöpfung, suggeriert ein radikales psychophysisches Umschmelzen der modernen Persönlichkeit und die Schaffung eines vollkommenen Künstler-Menschen, der die Macht des „Unbewussten“ zu überwinden und den Widerspruch zwischen Natur und Kultur, dem Prinzip der Realität und dem Lustprinzips im Raum des ästhetischen Spiels aufzulösen hat.

Key words: Avantgarde, Psychoanalyse, Freudomarxismus, Diskurs, Ästhetik, Soziologie, Moderne, Lebensgestaltung, «Pedologie».

The article contains an analysis of the convictions and arguments that characterize the utopian project of Freudo-Marxism in the context of the aesthetic program of the Russian avant-garde. The Freudo-Marxist synthesis is based on the avant-garde model of life-creation, suggesting a radical psychophysical remelting of the modern personality and the creation of a perfect human artist who can overcome the "unconscious" power and resolve the contradiction between nature and culture, between the principle of reality and the principle of pleasure in the space of aesthetic play.

Key words: avant-garde, psychoanalysis, Freudo-Marxism, discourse, aesthetics, sociology, modernism, life-creating, «pedology». 
Die Titelliste der Traumdeutung schmückte das lateinische Motto aus Virgils „Aeneis“: „Flectere si nequeo superos, Acheronta movebo“ (Kann ich die oberen Götter nicht beugen, so werde ich die Unterwelt in Bewegung setzen). Juno bedroht damit Jupiter. Freud war aber nicht der erste, der Junos Drohung als Motto vor sein Werk setzte. Er kannte diese Worte nicht direkt aus Virgil, sondern aus der politischen Kampfschrift von Ferdinand Lassalle: Der italienische Krieg und die Aufgabe Preußens (1859) (Schorske 1997: 188189). Lassalle, ein wichtiger Mitstreiter, zugleich ein Opponent von Marx, bedrohte die preußische Regierung durch das Aufrühren des politischen Acheron, d.h. durch die Revolution, durch ihre latent vorhandene Gewalt. Indem Freud Lassalles Motto sich zu eigen macht, überträgt er die angedeutete Umwälzung aus dem Bereich der Politik in den des Seelenlebens. Freuds Acheron ist das Bild für verdrängte Triebregungen, die jederzeit dazu bereit sind, die Oberwelt des Bewusstseins zu überfluten. An diesem Beispiel lässt sich formulieren, was unter Freudomarxismus zu verstehen ist: Die Rückübersetzung der Revolution aus der Psychologie in den Bereich der Politik. Sieht man jedoch genauer hin, so greift diese Definition zu kurz.

\section{Rahmenbegriffe: Futurismus, Symbolismus, Marxismus}

Als eigentliche Avantgardeschule gilt in russischer Literaturgeschichte der Futurismus. Man kann nicht behaupten, die Futuristen hätten die Psychoanalyse gar nicht wahrgenommen. Die Aufwertung des Unbewussten als einer Energie- und Inspirationsquelle, die Erfindung einer Experimentalsprache als Sprache des Unbewussten, die Theorie des automatischen oder „,momentanen“ Schreibens - diese Merkmale sind unter anderem auf die Psychoanalyse zurückzuführen, aber eben nur ,unter anderem“, in einem größeren Kontext der sog. ,gottlosen Mystik der Moderne“" (Spörl 1997).

Belege für die Freud-Lektüre sind spärlich. Man weiß etwa, dass ein gewisser Professor Charasov, der vermeintliche Freud-Kenner, eine Vorlesung mit dem Titel Sigmund Freuds Theorie und die Dichtung des Unsinns auf der Bühne des „Phantastischen Kabarett“ in Tiflis gehalten hat (Шукуров 2013: 71-73). Darauf ist die spätere Aufzeichnung von Aleksej Kručenych zu beziehen: „Wir freudieren ungehalten und unstimmig, betreiben psychoanalytische Verschiebungen“ (Крученых 1925: 59). ${ }^{1}$; „Die Kunst marschiert in der Avantgarde der psychischen Evolution“ (Крученых 1967: 66). ${ }^{2}$

Man weiß auch, dass Jakov Druskin, den Oberiuten, (d.h. der „Vereinigung der realen Kunst") nahestehender Denker, Freuds Texte übersetzte und vermittelte. So lässt sich annehmen, dass die Technik des absurden Witzes, möglicherweise im Zusammenhang mit der Freudschen Abhandlung Der Witz und seine Beziehung zum Unbewussten zu sehen ist (Schahadat 2004: 198).

\footnotetext{
1 „Мы фрейдыбачим на психоаналитике сдвигологических собачек, без удержу, вразброд“"

2 , Искусство марширует в авангарде психической эволюции“
} 
Schließen kann man daraus nur eines: Die Psychoanalyse gehörte zum kulturellen Kontextsystem der Avantgarde-Poetik, nicht weniger, aber auch nicht mehr. Kein Vergleich mit dem deutschen Expressionismus, dem französischen Surrealismus, dem Theater des Absurden. Ihre Vertreter befassten sich mit der Psychoanalyse viel eingehender als die Russen, als russische Futuristen.

Früher und folgenschwerer begegneten sich die Psychoanalyse und die literarische Moderne im Zeichen des Symbolismus und des Marxismus. Dementsprechend verlief die Diskussion in zwei Grundformen - der symbolistischen und der marxistischen. Diese zwei zentralen Gruppen von russischen Rezipienten erkannten in der Psychoanalyse ein großes weltanschaulich-ideologisches und produktionsästhetisches Potenzial und bemühten sich um die Übersetzung psychoanalytischer Konzepte in die eigene Sprache und die eigenen Diskurse.

Man dachte im Rahmen einer Alternative: Die Welt ist entweder heil, dann ist die Kunst im Ernst nicht nötig, oder die Welt ist unheil, dann ist die Kunst im Ernst zu schwach und kann nichts ausrichten. Im unheilen Russland des 19. Jahrhunderts wurde die Kunst so ernst genommen, dass zuerst Gogol und dann Tolstoj „die Vollkommenheit ihrer Kunstwerke der Mühe um die Vollendung des Lebens zum Opfer brachten“"(Stepun 1964: 98). Der Symbolismus übernimmt diese Geste des Verzichts auf die „Kunst der Kunstwerke“ (Nietzsche 1980: 9: 506), indem er sich nicht als eine Dichterschule, sondern als eine totale Revolution der Empfindungsweise und Denkungsart positioniert. Das gilt auch für den Marxismus, der als eine der Meistererzählungen der Moderne weit mehr als eine sozialwissenschaftliche Schule sein wollte und werden konnte.

Die Kunst ist die Funktion von etwas, das selbst nicht Kunst ist — so der gemeinsame Ausgangspunkt. Das Ziel wird jedoch gerade darin gesehen, dieses Etwas, die Gesamtheit der modernen Lebensformen, zur Kunst zu machen. Damit knüpfen beide Meistererzählungen einerseits an das romantische Konzept der ästhetischen Revolution, andererseits an das Projekt Avantgarde an. Definiert man den Avantgardismus über das Merkmal der Entdifferenzierung von Kunst und Leben (Bürger 1974: 72), so sind Symbolismus und Marxismus insofern als Avantgarde zu bezeichnen, als sie den Autonomie-Status der Kunst angreifen. Sie sind in dem Maße avantgardistisch, in dem sie die rationalistische Ausdifferenzierung der Kommunikationssysteme aufheben und durch eine Retotalisierung der Kultur ersetzen - im Sinne einer integralen Zukunftsgesellschaft und eines integralen „neuen Menschen“.

\section{A realibus ad realiora}

Freuds Menschen-und Kulturbild wurde nie kritiklos aufgenommen. Man hatte vieles auszusetzen: Positivismus und Pessimismus, das Bürgerliche und 
das Restitutive. Den ideologischen Hintergrund für die russische Auseinandersetzung mit der Tiefenpsychologie, für ihre Kritik und Umdeutung bildete der allgemeine weltanschauliche Monismus, der mit dem philosophischen nicht identisch war (Spörl 1997: 97-112). Die zeitgenössische Verwendung dieses Begriffs schwankte zwischen dem idealistischen und materialistischen Gebrauch. Den ersten vertrat der Symbolismus, den zweiten der Marxismus.

Die symbolistische Spielart wurde durch Vladimir Solov'evs Alleinheitsmetaphysik geprägt. Die materielle raumzeitliche Welt sei demnach ein noch nicht vollendetes, vorläufiges Sein, dessen wahre Urform (,realia in rebus") unerschlossen liege. Die sinnlich fassbare und die geistige Realität seien durch Symbole miteinander verbunden. Die Offenbarung dieser Relation zwischen zwei Welten in symbolischen Bildern verstand man als die Aufgabe einer magischen Kunst, die die Welt entgrenzen und als eine sinnlich-übersinnliche Totalität erschließen und neuschaffen sollte.

Die höchste Form des Schaffens bezeichnen die Symbolisten als ,theurgia“, als die Fortsetzung des göttlichen Schöpfungsaktes durch die menschliche Kunst. Man glaubt an die Leibwerdung des dichterischen Wortes, der Wortschöpfer gilt als Welten- und Menschenschöpfer. Andrey Belyj feiert den Symbolismus als ,den Anfang des Exodus des Dichters aus Ägypten der Kunstformen“ (Белый 1994: 465), Vjačeslav Ivanov als den Aufbruch in die „,wirkliche Wirklichkeit“, das Reich der „realiora“ (Иванов 1974: 553). Die Schlüsselrolle des vermittelnden Symbols erlaubt es, den Symbolismus in Einklang mit der Psychoanalyse zu bringen. Ein Psychotherapeut eignet sich das Autorenrecht des theurgischen Dichters an, des zweiten creator mundi (Смирнов 1994: 161). Auf dieser Basis werden hybride, freudianisch-symbolistische Konstruktionen möglich, wie etwa die Umdeutungen der Hysterie, des Narzissmus und Todestriebes im Sinne der Transgression, Verwandlung und Wiedergeburt. Späte Beispiele für diese Symbiose sind Die Destruktion als Ursache des Werdens (1912) von Sabina Spielrein und Narzissmus als Doppelrichtung (1921) von Lou Andreas-Salome.

Der Aufbruch in die ,wirklichste Wirklichkeit“, d.h. der Übergang ,a realibus ad realiora“" (Иванов 1974: 553) ist der Königsweg der Moderne. Die Kultur der Moderne misstraut der sinnlichen Wahrnehmung, spezialisiert sich auf die Suche nach dem Übersinnlichen oder auf der Archäologie der Tiefenstrukturen. Die realiora-Welt des Symbolismus ist die monistische Überrealität jenseits des Gegensatzes von Immanenz und Transzendenz. Die Marxisten bleiben im Bannkreis dieses mystischen Begriffs, ohne ihn selbst zu gebrauchen. Die „realiora“ des Marxismus ist die Welteinheit in ihrer Materialität, aber eine gesteigerte. Der Steigerungsfaktor ist das denkende Bewusstsein, eigenes Entwicklungsprodukt der Materie, das Instrument ihrer Selbstorganisation, das sie hervorbringt, um erkannt, geläutert und in den Zustand der Freiheit überführt zu werden. 


\section{Homo aestheticus}

Die marxistische Rezeption der Psychoanalyse entwickelte sich unter Protektion von Lev Trotzki, dem neben Lenin wichtigsten Theoretiker und Praktiker der Oktoberrevolution. Beide, Lenin und Trotzki, glauben an die Macht des Gedankens, daran, dass ein Gedanke zu einer materiellen Kraft werden kann. Der Bereich des Unbewussten sollte, so Trotzki, ebenso beherrscht und unter die Kontrolle der kollektiven Vernunft gestellt werden wie das Chaos der kapitalistischen Marktwirtschaft. Die Rolle, die dabei der Literatur und Kunst zukommt, erläutert er in seinem Werk Literatur und Revolution (1923), das seine literaturkritischen und kulturpolitischen Essays aus den Jahren 1907-1923 beinhaltet.

Mehrmals nimmt er darin auf Freud und seine Schule Bezug, die er während seines Aufenthalts in Wien, damals Weltmetropole der Psychoanalyse, kennengelernt hatte. Nach eigener Aussage besuchte er die Sitzungen der Psychoanalytischen Vereinigung, pflegte Kontakte mit den Freudianern und studierte ihre Werke (Троцкий 1927: 260). Belegt sind seine Kontakte mit Alfred Adler, der 1909 ein Referat mit dem Titel Zur Psychologie des Marxismus hielt (Etkind 1996: 282).

Der Essay Neujahrsgespräch über die Kunst, (1908) beginnt mit der Zeitund Orts-Angabe: „Wien, Herrengasse, Café Central, Silvesterabend“ (Trozki 1994: 278). In diesem Ambiente, so fingiert der Text, findet ein internationales Gespräch statt. Das Thema ist die synthetische Kunst der Zukunft. Sie werde nicht mehr in Museen und Bibliotheken eingesperrt bleiben, sondern unser ganzes Leben durchdringen und umgestalten. Der alte russische Emigrant, wohl Trotzkis ,alter ego“, formuliert die Hoffnung, dass der Mensch, sobald er sich durch den technischen Fortschritt von der Last und Not der Arbeit befreit, den Willen verspüren wird, das unberechenbare Element des Unbewussten in seiner eigenen Psyche zu beherrschen und seine Seelenkräfte für die schöpferische Gestaltung der schönen Lebensformen aufzubieten: „Meine Herren! Trinken wir auf diesen sorgenlosen, glücklichen, genialen Müßiggänger der Zukunft, Prosit Neujahr!“ (Trotzki 1994: 287)

Freuds therapeutische Praxis wird radikalisiert, mit der Dialektik von Entfremdung und Neukonstituierung eines säkularisierten Subjekts untermauert. Über die Anthropologie von Marx und Nietzsche hinaus greift Trotzki auf die humanistische Tradition zurück, wie sie vor allem in Schillers Über die ästhetische Erziehung des Menschen (1795) zum Ausdruck kommt. Nur dass bei Schiller die sittliche Vervollkommnung des Menschen durch die Kunst einen Schutz gegen das unsteuerbare Politische darstellen sollte, bei Trotzki ist dagegen das Humane, Politische und Ästhetische eigentlich identisch. 1908, als Trotzki seinen Essay verfasst, ist das avantgardistische Projekt erst im Entstehen. Trotzki prägt es mit, indem er die politische Revolution als eine ästhetische Tätigkeit definiert. Die Aufgabe der Revolution bestehe darin, die durch die kapitalistische Arbeitsteilung entstandene Spaltung und Verzerrung 
des Menschen aufzuheben und die ganze, vielseitige und vollentwickelte menschliche Persönlichkeit außerhalb der knechtischen Arbeit, im Freiraum des müßigen Spiels wiederherzustellen. Bei Marx klingt diese Tradition im 3. Band des Kapitals an, wo geschrieben steht, dass jenseits des Reiches der Notwendigkeit die menschliche Kraftentwicklung beginnt, die sich als Selbstzweck gilt — „das wahre Reich der Freiheit“ (Marx / Engels 1970: 828).

Noch deutlicher und empathischer wird das Konzept des neuen Experimentalmenschen am Schluss des Essays Die Kunst der Revolution und die sozialistische Kunst (1921) zum Ausdruck gebracht, in dem eine ,radikale psychophysische Umschmelzung des erstarrten Homo sapiens" in Aussicht gestellt wird (Trotzki 1994: 252). Bei Freud war die Kunst Tagtraum und Spielwelt eines unglücklichen Neurotikers, der sich im Medium seiner Phantasie das zu verschaffen sucht, was ihm im Leben versagt geblieben ist. Im Vortrag Der Dichter und das Phantasieren (1906) wird der Künstler mit dem spielenden Kind gleichgesetzt; wie dieses baut er sich Luftschlösser auf, richtet sich geschützte Zonen der Imagination ein, künstliche Paradiese, um dem beherrschten Lustprinzip ein Ventil zu verschaffen. In den Vorlesungen zur Einführung in die Psychoanalyse (1917) vergleicht Freud das Phantasieren mit der Einrichtung eines Naturschutzparks. Das Es, der Urwald unserer Wünsche, gewinnt hier für das Ich jenes Terrain zurück, das an das Über-Ich verlorengegangen ist (Freud 1969: X: 363). Trotzki, ,ein Träumer im Rock des Volkskommissars" (Etkind 1996: 292), interpretiert die Freudsche Anthropologie als Anleitung zur Bildung des Künstlermenschen. Trotzkis Künstler heißt Revolutionär. Er selbst und sämtliche Lebensformen seiner Zeit sind sein Stoff, den er in einer ästhetischen Form aufzuheben und zu einem Gesamtkunstwerk zu gestalten hat.

Viele Texte in Literatur und Revolution lassen sich als avantgardische Manifeste definieren. Sie entwerfen das Programm einer anthropologischen Utopie. In den nächsten Jahren wurden diese Ansichten von zahlreichen Populärwissenschaftlern und Publizisten weiterentwickelt, wie etwa von Georgij J. Malis, dem Verfasser von Psychoanalyse des Kommunismus (1924). Das Buch des zwanzigjährigen Psychologiestudenten beginnt mit der Feststellung: „Dass der Psychoanalyse bei uns heute so viel Raum zur Entfaltung gegeben wird, ist kein Zufall“" (Малис 1924: 3). Die Psychoanalyse wird als Waffe der Revolution gefeiert. Das Schussziel ist die bürgerliche Kultur. Sie zwinge den Menschen, immer mehr von seinen Wünschen zu verdrängen, weshalb mit der Zahl der Nervenkranken auch die Rolle der kulturellen kompensatorischen Ersatzprodukte steige, wie etwa Religion, Philosophie, Kunst. Erst in der kommunistischen Gesellschaft von morgen, deren qualvolle Geburt wir miterleben dürften, werde es, ähnlich wie in der Urgemeinschaft, nichts mehr zu verdrängen geben, weil allen Menschen Befriedigung jeder Art verschaffen werde. So werde es nicht der geistige Überbau, sondern die gesellschaftliche Ordnung im Ganzen sein, in der das Unbewusste seine Verwirklichung finde, nicht etwa eine Symphonie, sondern der ästhetische Staat. Der Staat als Kunstwerk, der 
Traum der Jahrhunderte, wie man ihn etwa aus Jakob Burkhardts Renaissancegeschichte kannte, war wieder da und schien in Erfüllung zu gehen.

Malis, ein Trotzki- und Freudverehrer, kehrt einen Gedanken um, den er aus Freuds Arbeit Die Widerstände gegen die Psychoanalyse (1925) kennen sollte:

Die menschliche Kultur ruht auf zwei Stützen, die eine ist die Beherrschung der Naturkräfte, die andere die Beschränkung unserer Triebe. Gefesselte Sklaven tragen den Thron der Herrscherin. Wehe, wenn sie befreit würden; der Thron würde umgeworfen, die Herrin mit Füßen getreten. Die Gesellschaft weiß dies und will nicht, dass davon gesprochen wird“" (Freud 1968: 104).

Genau davon will Malis in voller Offenheit sprechen. Seine Rede ist naiv und unreif, lässt sich aber bruchlos in ein weites Diskursfeld der internationalen Avantgarde einfügen - von Otto Gross über Wilhelm Reich bis Herbert Marcuse. In allen Spielarten gestaltet sich der Freudomarxismus als Gegenentwurf einer repressiven Zivilisation, der im Zeichen des Freudschen „Lustprinzips“ steht und den Traum von absoluter Freiheit für die „,verborgene Tendenz“ der Psychoanalyse hält (Marcuse 1965: 17).

Ein eigenes großes Thema bildet in diesem Kontext der französische Surrealismus, von dem es bei Maurice Nadeau, dem Historiographen der französischen Avantgarde, schlicht und einfach heißt: „Ohne Sigmund Freud wären die Surrealisten keine Surrealisten geworden“ (Nadeau 1965: 213). Das Manifeste du Surrealisme von André Breton erschien im selben Jahr 1924, wie die russische Broschüre von Georgij Malis. Breton möchte einen gleichermaßen magischen wie materialistischen Monismus triumphieren lassen, damit die psychische Umwandlung des Subjekts und die materielle Umwandlung der Gesellschaft mit einem einzigen Schwung unternommen werden können (Vgl. Starobinski 1973: 146-148). Der Name Freud und der Name Trotzki werden dabei — von Breton wie von Malis — in einem Atemzug genannt — von Breton als Schutzpatrone des Surrealismus, von Malis als Schutzpatrone des Freudomarxismus.

Als Institution für die praktische Umsetzung der Lebenskunsttheorie entstand in den zwanziger Jahren die Pädologie, eine Wissenschaft vom Umbau des Menschen. Der perfekte, harmonische Vollmensch sollte als eine Art plastisches Kunstwerk erschaffen werden. Der junge Sowjetstaat hatte seine pädagogische Provinz aufgebaut. In jeder sowjetischen Stadt gab es eine pädologische Lehranstalt, eine Art Steiner-Schule, nur auf der theoretischen Plattform des Freudomarxismus. Lunačarskij, der Komissar für Volksbildung, schrieb damals:

Neben der Pflanzen — und Viehzucht muss es eine weitere Wissenschaft dieser Art geben: Menschenzucht. Die Pädologie leuchtet uns auf dem entscheidenden Wege zur Herstellung des neuen Menschen, die parallel zur Produktion neuer Ausrüstungen in der Wirtschaft zu organisieren ist (Zit. Etkind 1996: 330; Anm. 477). 
Eine der pädologischen Elite-Schulen, das Kinderheim-Labor „Proletarische Solidarität“ sollt Stalins Sohn Wassilij besucht haben (Etkind 1996: 251). Als wissenschaftliche Autorität wurde der weltberühmte Physiologe Ivan Pavlov eingeschaltet. In einem öffentlichen Brief an ihn verwies Trotzki auf die Komplementarität zwischen der Psychoanalyse und der Pavlovschen Verhaltenslehre: Der Mechanismus der Sublimierung der Sexualenergie ließe sich als Basis für die Bildung bedingter Reflexe sehen (Троцкий 1927: 260). Die Idee der Freud-Pavlovscher Synthese fand auch in der Kunsttheorie Gehör. Unter den zeitgenössischen Künstlern war es kein geringerer als Sergej Eisenstein, der sie aufgriff, um sie auf das Problem der Steuerung archaischer Affekte durch die Kunst anzuwenden. Der Regisseur Mark Ermler erinnert, wie Eisenstein, selbst ein leidenschaftlicher Freud-Leser, ihn zurechtgewiesen hat: „Freud ist nicht der einzige in der Welt. Lies mal Ivan Pavlov“ (Etkind 1996: 394).

Die von Trozki angeregte Diskussion über die Vereinbarkeit von Freudismus und Marxismus blieb bis zum Ende der zwanziger Jahre aktuell. Zum Denkmal dieser Diskussion wurden wichtige kunsttheoretische Texte, darunter Psychologie der Kunst (verfasst 1925, erstmals veröffentlicht 1965) von Lev Vygotskij (Vgl. Hansen-Löve 1978: 426-436) und die kritische Studie Frejdism (1927) von Valentin Vološinov (Vgl. Freise 1993: 163-170), die er in enger Zusammenarbeit mit Michail Bachtin verfasste. Der Grundton ist kritisch und die Kritik scheint in eine einheitliche Richtung zu weisen: Ungeschichtlichkeit, Entzeitlichung aus Angst vor der politischen Realität.

\section{Leitdiskurs Kunst}

Dass die avantgardistische Poetik sich durch die „Dominantsetzung außerästhetischer Funktionen kennzeichnet" (Günther 1978: 80) und ihr Anspruch auf die Retotalisierung der Kultur politisch dominiert gewesen ist (Plumpe 2001: 10), gehört, spätestens seit Peter Bürgers Theorie der Avantgarde (1974) zur Topik der Avantgardeforschung, scheint jedoch nicht uneingeschränkt zutreffend zu sein, (zumindest in Bezug auf Politik als Leitdiskurs). Möglicherweise kann so etwas festgestellt werden, wie die List der Kunstautonomie. Das heißt, die energische Betonung der Unabhängigkeit und Selbstgesetzgebung der Kunst, wie sie seit der Goethezeit bekannt ist, verbindet sich schon damals unmittelbar und fast automatisch mit der Erweiterung der Macht des Kunstdiskurses auf sämtliche Nachbardiskurse des kulturellen Feldes. Ähnlich wie in der Avantgarde bildet der Bereich der Kunst gleichsam einen militärischen Stützpunkt, von dem aus der gesamte Kulturraum erobert werden soll. Die Emanzipation denkt die Expansion mit, die auf ,die Herrschaft der Kunst über das Leben“ (Nietzsche 1980: 1: 889) abzielt.

Kennzeichnend ist die avantgardistische These vom „Ende der Kunst“. „Kapitalismus, sagt Franz Kafka, ist der Zustand der Welt und der Seele — 
alles ist abhängig, alles ist gefesselt" (Janouch 1968: 164). Ein Teil von diesem „alles“ ist auch die institutionell gefesselte Kunst. Ihr Ende wird von den russischen Avantgardisten (Majakovskij, Tret‘jakov, Čužak, Brik, Arvatov) im Zusammenhang mit dem Ende der bürgerlichen Ordnung schlechthin gesehen, mit der Abschaffung bürgerlicher Arbeitsteilung und funktionaler Systemdifferenzierung, die für die Versklavung des Menschen verantwortlich gemacht werden. Wenn die institutionell gefesselte Kunst sich selbst in der Avantgarde zurücknimmt, dann nicht deswegen, weil sie sich der Politik unterwirft, sondern weil ihr Anspruch auf die absolute Herrschaft durch die Geschichte anerkannt, durch die politische Revolution bestätigt worden ist. Avantgardistisch wusste sich die Kunst spätestens seit dem Symbolismus mit dessen theurgischem Konzept. Doch fühlte man noch keine Armee hinter sich. Erst die Oktoberrevolution gab dem Künstler für eine bestimmte Zeit die euphorische Gewissheit, einer Gesellschaft voranzuschreiten, die als Ganzes einem ästhetischen Zustand zustrebt.

„Jeder wird ein Künstler sein, ein vollendeter Meister in der Sache, die er im jeweiligen Augenblick betreibt" (Zit.: Wilbert 1976: 194). Das schreibt Sergej Tret'jakov, könnte aber auch bei Schiller stehen. Hier ist die Drehscheibe zwischen der deutschen Kunstperiode und der russischen Avantgarde, deren übereinstimmende Kunstgläubigkeit den Anfang und das Ende der Moderne als Makroepoche aufeinander beziehen lässt. Wie die russische Avantgarde insgesamt ist auch die kurze Episode des Freudomarxismus ein Bestandteil des dynamischen internationalen Kontextes der ästhetischen Revolution. Seine Bedeutung liegt nicht im Bereich der Politik oder Psychologie, sondern in dem der Kunst, auf Seiten des Mythos, dessen Poetik er darstellt.

\section{LITERATUR}

Bürger Peter. Theorie der Avantgarde. Frankfurt a. M.: Suhrkamp, 1974.

Etkind Alexander. Eros des Unmöglichen. Die Geschichte der Psychoanalyse in Russland. Aus dem Russischen von Andreas Tretner. Leipzig: Gustav Kiepenheuer, 1996.

Freise Matthias. Michail Bachtins philosophische Ästhetik der Literatur. [Slavische Literaturen. Texte und Abhandlungen. Hrsg. Von Wolf Schmid. Bd. 4]. Frankfurt a. M.: Peter Lang, 1992.

Freud Sigmund (1968, zuerst 1925). „Die Widerstände gegen die Psychoanalyse“. Freud Sigmund. Gesammelte Werke. Hrsg. von A. Freud et al. Bd. IV: Werke aus den Jahren 1925-1931. Frankfurt a. M.: S. Fischer, 1968: 97-110.

Freud Sigmund. Studienausgabe in 10 Bänden. Frankfurt a. M.: S. Fischer, 1969.

Günther Hans. „Die These vom Ende der Kunst in der sowjetischen Avantgarde der 20er Jahre“. Referate und Beiträge zum VIII. Internationalen Slavistenkongress. Zagreb 1978. München: Sagner, 1978: 71-90.

Hansen-Löve Aage. Der russische Formalismus. Methodologische Rekonstruktion seiner Entwicklung aus dem Prinzip der Verfremdung. Wien: Verlag der österreichischen Akademie der Wiss., 1978. 
Janouch Gustav. Gespräche mit Kafka. Aufzeichnungen und Erinnerungen. Frankfurt a. M.: S. Fischer, 1968.

Marcuse Herbert. Triebstruktur und Gesellschaft. Ein philosophischer Beitrag zu Sigmund Freud [zuerst 1955 al „Eros und Zivilisation“]. Frankfurt a. M.: Suhrkamp, 1965.

Marx, Karl / Engels Friedrich. Werke in 44 Bänden. Bd. 25: Das Kapital. Bd. III. Berlin: Karl Dietz Verlag, 1970.

Nadeau Maurice. Geschichte des Surrealismus. Reinbek bei Hamburg: Rowohlt, 1965.

Nietzsche Friedrich. Sämtliche Werke. Kritische Studienausgabe in 15 Bänden. Hrsg. von Georgio Colli und Mazzino Montinari. Bd. 1: Die Geburt der Tragödie; Bd. 9: Nachgelassene Fragmente 1880-1882. Berlin — New York: De Gruyter, 1980.

Plumpe Gerhard. „Avantgarde. Zum historischen Ort ihrer Programme“. Text + Kritik. Sonderband IX/01: Aufbruch ins 20. Jahrhundert. Über Avantgarden. Hrsg: H. L. Arnold. München: Edition text+kritik, 2001: 7-16.

Schahadat Schamma. Das Leben zur Kunst machen. Lebenskunst in Russland vom 16. Bis zum 20. Jahrhundert. München: W. Fink, 2004.

Schorske Carl E. Wien. Geist und Gesellschaft im Fin de Siècle. Aus dem Amerikanischen von Horst Günter. München — Zürich: S. Fischer, 1997.

Spörl Uwe. Gottlose Mystik in der deutschen Literatur um die Jahrhundertwende. Paderborn — München — Wien — Zürich: Schöning, 1997.

Starobinski Jean. Psychoanalyse und Revolution. Aus dem Französischen von Eckhart Rohloff. Frankfurt a. M.: Suhrkamp, 1973.

Stepun Fedor. Mystische Weltschau. Fünf Gestalten des russischen Symbolismus. München: Hanser, 1964.

Trozki Leo. „Neujahrsgespräch über die Kunst“. Trozki Leo. Literatur und Revolution. Aus dem Russischen von Eugen Schäfer u. Hans von Riesen. Essen: Arbeiterpresse-Verl., 1994: 278-287.

Wilbert Gerd. Die Entstehung und Entwicklung des Programms der ,,linken“ Kunst und der „Linken Front der Künste“ (LEF) 1917-1925: Zum Verhältnis von künstlerischer Intelligenz und sozialistischer Revolution in Sowjetrussland. Gießen: Schmitz, 1976.

Белый Андрей. «Революция и культура». Белый Андрей. Критика. Эстетика. Теория символизма. В 2 т. Т. 2. М.: Искусство, 1994: 453-465.

Иванов Вячеслав. «Две стихии в современном символизме». Иванов Вячеслав. Собрание сочинений. В 4 т./под ред. Д. Иванова, О. Дешарт. Т. 2. Bruxelles: Foyer oriental Chrétien, 1971-1974: 536-561.

Крученых Алексей. Декларация №5. О заумном языке и современной литературе. М.: Всероссийский союз поэтов, 1925: 57-59.

Крученых Алексей. «Новые пути слова». Манифесты и программы русских футуристов / под ред. В. Маркова. München: Fink 1967: 65-68.

Малис Георгий. Психоанализ коммунизма. С предисловием проф. К.И. Платонова. Харьков: Космос, 1924.

Смирнов Игорь. Психодиахронологика: Психоистория русской литературы от романтизма до наших дней. М.: Новое литературное обозрение, 1994: 161.

Троцкий Лев. Сочинения. Т. 21: Культура переходного периода. М. — Л.: Госиздат, 1927.

Шукуров Дмитрий. Русский литературный авангард и психоанализ в контексте интеллектуальной культуры Серебряного века. М.: Языки славянской культуры, 2014.

\section{LITERATURE}

Belyj Andrej. „Revolyuciia i kul'tura“. Belyj Andrej. Kritika. Estetika. Teoriia simvolizma. M.: Iskusstvo, 1994: 453-465.

Bürger Peter. Theorie der Avantgarde. Frankfurt a. M.: Suhrkamp, 1974. 
Etkind Alexander. Eros des Unmöglichen. Die Geschichte der Psychoanalyse in Russland. Aus dem Russischen von Andreas Tretner. Leipzig: Gustav Kiepenheuer, 1996.

Freise Matthias. Michail Bachtins philosophische Ästhetik der Literatur. [Slavische Literaturen. Texte und Abhandlungen. Hrsg. Von Wolf Schmid. Bd. 4]. Frankfurt a. M.: Peter Lang, 1992.

Freud Sigmund (1968, zuerst 1925). „Die Widerstände gegen die Psychoanalyse“. Freud Sigmund. Gesammelte Werke. Hrsg. von A. Freud et al. Bd. IV: Werke aus den Jahren 1925-1931. Frankfurt a. M.: S. Fischer, 1968: 97-110.

Freud Sigmund. Studienausgabe in 10 Bänden. Frankfurt a. M.: S. Fischer, 1969.

Günther Hans. „Die These vom Ende der Kunst in der sowjetischen Avantgarde der 20er Jahre“. Referate und Beiträge zum VIII. Internationalen Slavistenkongress. Zagreb 1978. München: Sagner, 1978: 71-90.

Hansen-Löve Aage. Der russische Formalismus. Methodologische Rekonstruktion seiner Entwicklung aus dem Prinzip der Verfremdung. Wien: Verlag der österreichischen Akademie der Wiss., 1978.

Ivanov Vyacheslav. „Dve stikhii v sovremennom simvolisme“. Ivanov Vyacheslav. Sobranie sochinenij. T. 1-4/Pod redakciej D. Ivanova, O. Dechart. T. 2. Bruxelles: Foyer oriental Chrétien, 1971-1974: 536-561.

Janouch Gustav. Gespräche mit Kafka. Aufzeichnungen und Erinnerungen. Frankfurt a. M.: S. Fischer, 1968.

Kruchenykh Aleksei. „Deklaratsiia № 5. O zaumnom iazyke i sovremennoi literature“. M.: Vserossiyskii soiuz poetov, 1925: 57-59.

Kruchenykh Aleksei. „Novye puti slova“. Manifesty i programmy russkikh futuristov. Ed. V. Markov. Munich: Fink, 1967: 65-68.

Malis Georgii. Psihoanaliz kommunizma. Khar'kov: Kosmos, 1924.

Marcuse Herbert. Triebstruktur und Gesellschaft. Ein philosophischer Beitrag zu Sigmund Freud [zuerst 1955 al „Eros und Zivilisation“]. Frankfurt a. M.: Suhrkamp, 1965.

Marx, Karl / Engels Friedrich. Werke in 44 Bänden. Bd. 25: Das Kapital. Bd. III. Berlin: Karl Dietz Verlag, 1970. Nadeau Maurice. Geschichte des Surrealismus. Reinbek bei Hamburg: Rowohlt, 1965.

Nietzsche Friedrich. Sämtliche Werke. Kritische Studienausgabe in 15 Bänden. Hrsg. von Georgio Colli und Mazzino Montinari. Bd. 1: Die Geburt der Tragödie; Bd. 9: Nachgelassene Fragmente 1880-1882. Berlin — New York: De Gruyter, 1980.

Plumpe Gerhard. „Avantgarde. Zum historischen Ort ihrer Programme“. Text + Kritik. Sonderband IX/01: Aufbruch ins 20. Jahrhundert. Über Avantgarden. Hrsg: H. L. Arnold. München: Edition text+kritik, 2001: 7-16.

Schahadat Schamma. Das Leben zur Kunst machen. Lebenskunst in Russland vom 16. Bis zum 20. Jahrhunder $t$. München: W. Fink, 2004.

Schorske Carl E. Wien. Geist und Gesellschaft im Fin de Siècle. Aus dem Amerikanischen von Horst Günter. München — Zürich: S. Fischer, 1997.

Shukurov Dmitrij. Russkij literaturnyj avangard i psikhoanaliz v kontekste intellektual'noj kul'tury Serebryanogo veka. M.: Yazyki slavyanskoy kultury, 2014.

Spörl Uwe. Gottlose Mystik in der deutschen Literatur um die Jahrhundertwende. Paderborn — München — Wien — Zürich: Schöning, 1997.

Starobinski Jean. Psychoanalyse und Revolution. Aus dem Französischen von Eckhart Rohloff. Frankfurt a. M.: Suhrkamp, 1973.

Stepun Fedor. Mystische Weltschau. Fünf Gestalten des russischen Symbolismus. München: Hanser, 1964.

Trozki Leo (1994). „Neujahrsgespräch über die Kunst“. Trozki Leo. Literatur und Revolution. Aus dem Russischen von Eugen Schäfer u. Hans von Riesen. Essen: Arbeiterpresse-Verl., 1994: 278-287.

Troczkiy Lev. Sochineniia. T. 21: Kul'tura perekhodnogo perioda. M. — L.: Gosizdat, 1927. 
Wilbert Gerd. Die Entstehung und Entwicklung des Programms der „linken“ Kunst und der „Linken Front der Künste“ (LEF) 1917-1925: Zum Verhältnis von künstlerischer Intelligenz und sozialistischer Revolution in Sowjetrussland. Gießen: Schmitz, 1976.

\section{Алексей Жеребин}

\section{РУССКИЙ ФРЕЙДОМАРКСИЗМ В ДИСКУРСИВНОМ ПОЛЕ ИСТОРИЧЕСКОГО АВАНГАРДА}

\section{Резюме}

Статья содержит анализ убеждений и аргументов, характеризующих утопический проект фрейдомарксизма в контексте эстетической программы русского авангарда, где психология пересекается с социологией и поэтика неотделима от политики. В основе фрейдомарксистского синтеза лежит авангардистская модель жизнетворчества, предполагающую радикальную психофизическую переплавку современной личности и создание совершенного человека-художника, способного преодолеть власть «бессознательного» и разрешить противоречие между природой и культурой, «принципом реальности» и «принципом удовольствия» в пространстве эстетической игры.

Ключевые слова: авангард, психоанализ, фрейдомарксизм, дискурс, эстетика, социология, модерн, жизнетворчество, педология.

\section{Алексеј Жеребин \\ РУСКИ ФРОЈДОМАРКСИЗАМ У ДИСКУРСИВНОМ ПОљУ ИСТОРИЈСКЕ АВАНГАРДЕ}

\section{Резиме}

Рад садржи анализу уверења и аргумената, који карактеришу утопистички пројекат фројдомарксизма у контексту естетичког програма руске авангарде, где се стичу психологија и социологија, и поетика је неодвојива од политике. У основи фројдомарксистичке синтезе лежи авангардни модел стварања живота, који подразумева радикално психофизичко преиначавање савремене личности и стварање савршеног човекауметника, способног да превазиђе власт „несвесног“ и реши противречност између природе и културе, „принципа реалности“ и „принципа задовољства“ у простору естетичке игре.

Кључне речи: авангарда, психоанализа, фројдомарксизам, дискурс, естетика, социологија, сецесија, стварање живота, педологија. 